\title{
Hypersensitivity reaction to Sporothrix schenckii: erythema nodosum associated with sporotrichosis
}

\author{
Francine Papaiordanou ${ }^{[1]}$, Bruno Rebelo Lages da Silveira ${ }^{[1]}$ \\ and Luna Azulay Abulafia ${ }^{[1],[2]}$
}

[1]. Santa Casa da Misericórdia do Rio de Janeiro, Instituto de Dermatologia Prof. Rubem David Azulay, São Paulo, Brasil. [2]. Setor de Dermatologia, Hospital Universitário Pedro Ernesto, Universidade do Estado do Rio de Janeiro, Rio de Janeiro, Brasil.

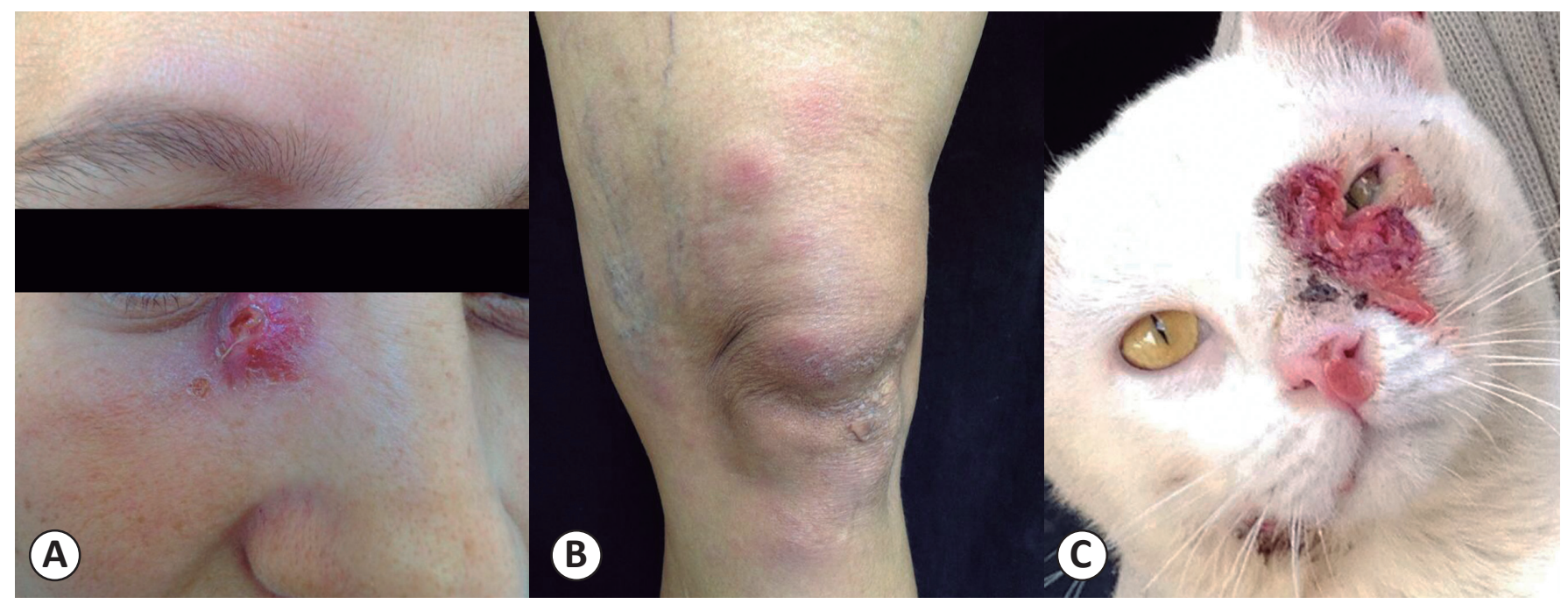

A 42-year-old female patient visited the dermatology clinic complaining of having had a wound in the face for 25 days. She reported that her cat had scratched her in the inner corner of her right eye. The scratch evolved to local edema and erythema and, a week later, to ulceration with infiltrated edges and a purulent exudate (Figure A). She also reported, simultaneous with ulceration emergence, the onset of lower limb edema associated with painful and erythematous nodules, which were more palpable than visible, up to the inguinal region (Figure B). The patient reported no other symptoms.

The patient brought her cat to the hospital on the day of consultation. The cat had ulceration in the inner corner of the left eye and a submandibular ulcer (Figure C). A diagnosis of sporotrichosis associated with erythema nodosum was reached and treatment with $400 \mathrm{mg} /$ day itraconazole $(200 \mathrm{mg} / 12 \mathrm{~h}$ for 90 days) was indicated.

Samples were collected from the cat for direct mycological examination. A sample from the patient's ulceration was also collected for culture to confirm the diagnosis (humid, compact, white lesions and whitish colonies with a wrinkled surface in the darkened aerial mycelium). Microscopic examination of the culture showed thin-walled hyphae with oval or triangular conidia at the top of the conidiophores. The cat was referred to Oswaldo Cruz Foundation [Fundação Oswaldo Cruz (FIOCRUZ)] for treatment. By December 2009, more than 2000 people and 3,200 cats had been treated for confirmed sporotrichosis at FIOCRUZ.

\section{REFERENCES}

1. de Lima Barros MB, Schubach AO, Carvalhaes de Oliveira RV, Martins EB, Teixeira JL, Wanke B. Treatment of cutaneous sporotrichosis with itraconazole - study of 645 patients. Clin Infec Dis 2011; 52:e200-e206.

2. Galhardo MC, De Oliveira RM, Valle AC, Paes RA, Silvatavares PM, Monzon A, et al. Molecular epidemiology and antifungal susceptibility patterns of Sporothrix schenckii isolates from a cattransmitted epidemic of sporotrichosis in Rio de Janeiro, Brazil. Med Mycol 2008; 46:141-151.

3. Lloret A, Hartmann K, Pennisi MG, Ferrer L, Addie D, Belák S, et al. Sporotrichosis in cats: ABCD guidelines on prevention and management. J Feline Surg 2013; 15:619-623.

Corresponding author: Dr Francine Papaiordanou. Rua Careaçú 548, Jardim França, 02339-000 São Paulo, Brasil.

Phone: 55 11 9-9939-0000

e-mail: francinepapaiordanou@gmail.com

Received 1 April 2015

Accepted 4 May 2015 